\title{
Use of Prosopis laevigata Seed Gum and Opuntia ficus-indica Mucilage for the Treatment of Municipal Wastewaters by Coagulation-Flocculation
}

\author{
Luis G. Torres ${ }^{1}$, Sandra L. Carpinteyro-Urban ${ }^{1}$, Mabel Vaca ${ }^{2}$ \\ ${ }^{1}$ Department of Bioprocesses, Unidad Profesional Interdisciplinaria de Biotecnología UPIBI-Instituto Politécnico Nacional, Mexico \\ City, Mexico; ${ }^{2}$ Departamento de Energía, Universidad Autónoma Metropolitana, Unidad Azcapotzalco, Mexico City, Mexico. \\ Email: 1torresbustillos@gmail.com
}

Received December $6^{\text {th }}, 2011$; revised February $14^{\text {th }}, 2012$; accepted February $22^{\text {nd }}, 2012$

\begin{abstract}
Prosopis laevigata and Opuntia ficus-indica grow in arid and semiarid regions of Mexico and other countries. Both produce biopolymers with interesting characteristics from the rheological point of view as well as because of their coagulating-flocculating capabilities. Prosopis produce galactomannans inside the endosperm, very similar to those found in guar, locust bean, and tara gums. Opuntia sp. produces mucilage that contains polygalacturonic acid and five neutral sugars. Prosopis seed gum has not been proposed to be used as coagulant-flocculant before. In the case of Opuntia mucilage, some authors have suggested its use in the treatment of waters, using either the mucilage or the whole cladode powder. The use of these products in the treatment of municipal or even industrial wastewaters could give rise to diverse benefits. From the environmental point of view, treated waters with neither Fe nor Al, nor synthetic polymers would be obtained (with less toxicity risk). Besides, the produced sludges would be smaller in amount, with better biodegradability, and lower metals content. From the economical point of view, the use of these biopolymers would give an added value to the Opuntia and Prosopis culture in Mexico, helping small communities to enhance their incomes by producing environmental-friendly products. This work shows that both Prosopis galactomannan and Opuntia mucilage can be used to treat municipal wastewaters with an initial organic charge of about $827 \mathrm{mg} / \mathrm{L}$ as COD by the coagulation-flocculation process, with COD removals for the mesquite seed gum of up to $90 \%(\mathrm{pH} 10$, dose of $75 \mathrm{mg} / \mathrm{L}$ ) and of $60 \%(\mathrm{pH} 7$, doses of 50 and $150 \mathrm{mg} / \mathrm{L}$ ). In the case of mucilage, $65 \%$ of the initial COD was removed at $\mathrm{pH} 10$ (dose of $50 \mathrm{mg} / \mathrm{L}$ ). These figures are very promising for the treatment of wastewaters, with environmental-friendly products.
\end{abstract}

Keywords: Biopolymers; Coagulation; Flocculation; Opuntia ficus Mucilage; Prosopis laevigata Seed Gum; Wastewaters

\section{Introduction}

Prosopis laevigata (Humb. Et Bonpl. Ex Wild), also known as Prosopis dulcis, Mimosa rotundata, Neltuma laevigata and Acacia laevigata (among others), is a tree with maximum height of up to $13 \mathrm{~m}$ and a diameter of $0.8 \mathrm{~m}$ (Figure 1). This tree is widely distributed in South America (Venezuela and Colombia), Panama, The Antilles and Mexico. In Mexico, Prosopis sp. is found in the pacific coast from Michoacan down to Oaxaca and near the Gulf of Mexico (i.e., in Nuevo Leon, Tamaulipas and the north of Veracruz). It is also distributed in central regions up to 2300 masl, such as San Luis Potosí, Guanajuato, Zacatecas, Durango, Coahuila and Hidalgo [1]. This plant has been introduced into India and spread all over the country particularly in the semi-arid and wastelands [2].
The whole tree is used as a source of firewood and its pods are used as fodder for cattle (sheep and goats). The endosperm portion of the seed contains galactomannan gum, very similar to guar gum.

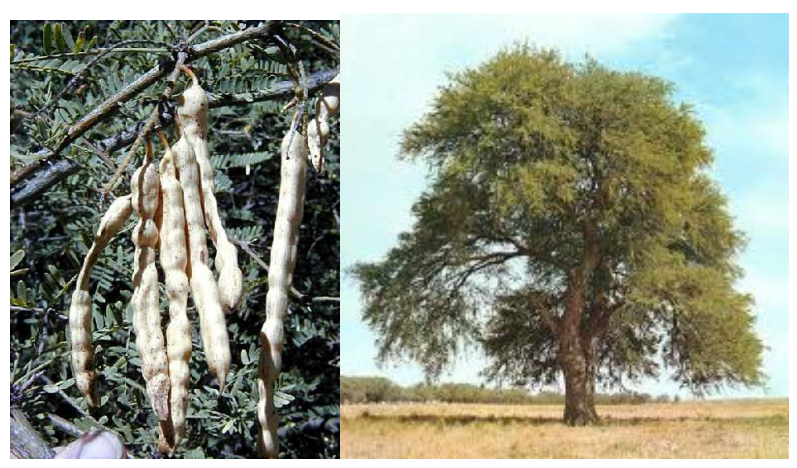

Figure 1. Prosopis laevigata tree and pods. 
The two best studied galactomannans-producing Prosopis species are $P$. juliflora [2,3] and P. pallida [4]. In Mexico, this species is known as mesquite. In order to differentiate the plant exudates and the gum contained inside the endosperm, this gum will be called seed gum.

The Prosopis galactomannans share many characteristics with other related galactomannans such as locust bean, guar and tara gums [4]. These characteristics include its capabilities as thickening agents, the low surface tension of gum dispersions, the tendency to form gels alone or when combined with other gums (such as carrageenan, agar and xanthan gum). Finally, galactomannans can act as a coagulant-flocculant agent for treating wastewaters and waters for human consumption [5].

Galactomanans have been obtained traditionally from Cyamopsis tetragonolobo (guar gum), Caesalipina spinosa (tara gum), and Ceratonia siliqua (locust bean gum). Besides, there are reports of other species of Leguminosae galactomannan producers such as Adenanthera pavonina, Caesalpinia pulcherrrima, Gleditsia triacanthos, and Sophora japonica [6].

Other known legume galacomannan-polysaccharides are fenugreek (from Trigonellafoenum graecum), cassia (from Casia tora), lucerne (from Medicago sativa), and clover (from Trifolium pretense) [2].

Opuntia ficus-indica is a cactaceae from arid and semiarid regions, in the form of shrub or tree up to $5 \mathrm{~m}$ tall, forming a sturdy trunk when aging (Figure 2). This species is native from Mexico, but it was introduced into Southern Europe, Africa and India a long time ago [7]. Traditionally, it is used for defensive hedge, as support for cochineal production of dyes (acaraminic acid), fodder, and its edible fruit, known as prickly pear, is consumed widely in Mexico. The boiled cladodes are edible and very frequently used in the Mexicans diet in dishes such as salads, soups or main dish, combined with hot sauces and meat.

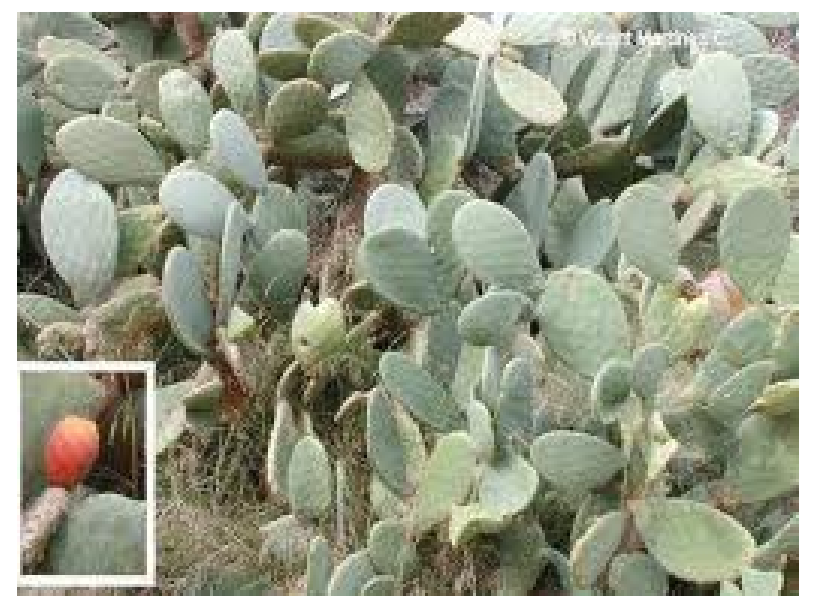

Figure 2. Opuntia ficus indica shrub and fruit.
The biophysical limits for Opuntia sp. are the following. Altitude 0 - 2600 masl. Mean annual temperature $18^{\circ} \mathrm{C}$ $26^{\circ} \mathrm{C}$. Mean annual rainfall from 150 - $600 \mathrm{~mm}$ [8].

The mucilage extracted from the cladodes of Opuntia $s p$. contains basically polygalacturonic acid (very similar to pectin structure), plus residues of some sugars such as D-galactose, D-xylose, L-arabinose, L-rhamnose, and D-galacturonic acid [9]. Some authors have already suggested that Opuntia $s p$. mucilage has a functional component with industrial perspectives [10], and have reported papers regarding its extraction and characterization [11].

Reference [12] have reported an excellent review about pectins from Opuntia sp. Authors have established the pectin content of some species and of some fruits (for comparison purposes), as well as the sugar composition of Opuntia mucilage extracted by an alkaline process. Finally, they have discussed the properties of the obtained mucilage including gelling, rheological and physiological properties of pectin.

The use of Opuntia $s p$. as coagulant in water treatment has been reported by some authors [10,13]. Besides, [14] have reported the use of Opuntia streptacantha as a low cost biosorbent for lead in water treatment.

Though the use of Opuntia sp. mucilage (or the whole cladode dry powder) has been proposed as a coagulantflocculant agent, most of these works used real or simulated wastewaters (most of them simulated ones) where only changes in turbidity have proven the efficiency of Opuntia mucilage as coagulant-flocculant agent $[13,15]$. In another work [16], the whole cladode, dried and milled was used as a coagulant-flocculant agent with excellent results.

The coagulation-flocculation process has been applied to treat municipal and industrial wastewaters. The system has many advantages over other treatment systems. One problem associated with this methodology is the generation of residual sludges. Very frequently these sludges contain high amount of metals, since the preferred coagulants are salts of $\mathrm{Al}$ and $\mathrm{Fe}$. These metals make the sludges difficult to treat by biological methods. Biochemical to chemical oxygen demand ratios, BOD/COD, could be low for these sludges.

Preliminary results [17] indicate that biopolymers work as coagulant-flocculant elements, producing fair values of COD, turbidity and salts removal, with slight changes in the final $\mathrm{pH}$. In comparison with the use of ferric chloride, the use of polysaccharides (in particular, mesquite seed gum and Opuntia mucilage) seems to be very promising.

The use of natural coagulant-flocculants will promote more biodegradable sludges at the end of the process. In this work, the use of natural polymers such as guar, lo- 
cust bean, and mesquite seed gum, as well as Opuntia indica mucilage is proposed. Guar and locust bean gums are galactomannans produced by plants from the Leguminosae genus.

Finally, the coagulation-flocculation capabilities of all these biopolymers were compared to the use of $\mathrm{FeCl}_{3}$, a chemical coagulant very frequently employed in wastewater treatment. It is important to remark that no synthetic polymer will be added after $\mathrm{FeCl}_{3}$ addition. This fact would seem disadvantageous for $\mathrm{FeCl}_{3}$, but it has been reported that the use of a synthetic polymer can promote additional COD removals of around 10\% - 15\% to that obtained only with $\mathrm{FeCl}_{3}$ [18].

The use of these seed gum and mucilage products obtained from plants widely distributed in arid zones of Mexico will contribute to give added value to the culture of Opuntia ficus indica and Prosopis laevigata.

\section{Materials and Methods}

\subsection{Biopolymers}

Biopolymers guar and locust bean gums (LBG) were purchased at Drogueria Cosmopolita (Mexico City, Mexico). HTPC- or cosmedia guar (a cationic derivative of guar gum) was purchased at Grupo Lar (Mexico, D. F., Mexico).

Opuntia cladodes without spines were purchased in a public market (Mexico City, Mexico). Cladodes were washed repeatedly with tap water. Mucilage was produced by boiling the cladodes cut in small pieces, until the material was light green and soft (20 - $30 \mathrm{~min})$. Cladodes cuts were separated from the mucilage solution using a rough sieve. Total (TS) and volatile solids (VS) were determined according to [19]. VS were used to calculate mucilage concentration.

Mesquite seed gum was produced as follows. Pods were collected in an arid region of the state of Guanajuato (Mexico). The endosperms are inside the pods, covered by a stiff layer, very similar to lentils. Endosperms were extracted using $\mathrm{NaOH}$-diluted solutions. Afterwards, endosperms were milled and sieved. The white-creamy powder was washed using ethanol in a Soxhlet system, until no oil remained. The powder was dried at environmental temperature and stored in a glass flask until its use.

\subsection{Jar Test Experiments}

All biopolymers were employed in solutions with concentrations from 50 to $150 \mathrm{mg} / \mathrm{L}$. Ferric chloride (J. T. Baker, Mexico) was employed for comparison purposes at the same concentrations. Jar-test equipment was used with beakers containing $1 \mathrm{~L}$ of wastewater. The removals of COD, turbidity and dissolved salts (measured as electri- cal conductivity), as well as the changes in the $\mathrm{pH}$ values, were measured following [19]. Municipal wastewaters were sampled from San Juan Ixhuatepec wastewater treatment plant (Estado de Mexico) at the influent, after the screens that remove large particles and big plastic materials. Sludge volumes were measured using 1-L Imhoff cones during $60 \mathrm{~min}$.

\section{Results and Discussion}

\subsection{Characterization of the Wastewaters}

General characteristics of the actual municipal wastewaters are those presented in Table 1. The COD value of the stream $(827 \mathrm{mg} / \mathrm{L})$ resulted quite high for a municipal wastewater. The ratio $\mathrm{BOD} / \mathrm{COD}$ resulted in 0.53 , which means that about half of the present material could be degraded by microbial means. In other measurements (data not shown), it was determined that $\mathrm{COD}_{\mathrm{T}} / \mathrm{CODs}$ is about $0.56, \mathrm{COD}_{\mathrm{T}}$ and $\mathrm{COD}$ represent the total, CODs and the dissolved fraction, respectively.

The $\mathrm{pH}$ value of wastewater was rather acid, and conductivity was about $1900 \mu \mathrm{S}$. Hardness was $288 \mathrm{mg} / \mathrm{L}$, MBAS was $4.1 \mathrm{mg} / \mathrm{L}$ and grease and oils were $230 \mathrm{mg} / \mathrm{L}$. All metals evaluated were present at rather low values, except $\mathrm{Cr}$, which was below the detection limit.

\subsection{Effect of Concentration in Coagulation-Flocculation Experiments}

Three experiments were carried out using the jar-test system. Four different concentrations of the biopolymer (or $\mathrm{FeCl}_{3}$ ) were studied $(50,75,125$, and $150 \mathrm{mg} / \mathrm{L})$. In a second experiment, the dose was fixed at $75 \mathrm{mg} / \mathrm{L}$ and $\mathrm{pH}$ was modified. In a third experiment, $\mathrm{pH}$ was adjusted to 10 and the dose of coagulant-flocculant agents was modified.

Table 1. Wastewater initial conditions.

\begin{tabular}{cccc}
\hline Parameter & Value & Parameter & Value \\
\hline $\mathrm{pH}$ & $6.69 \mathrm{units}$ & $\begin{array}{c}\text { Hardness as } \\
\mathrm{CaCO}_{3}\end{array}$ & $288.81 \mathrm{mg} / \mathrm{L}$ \\
Conductivity & $1869 \mu \mathrm{S}$ & $\mathrm{MBAS}$ & $4.14 \mathrm{mg} / \mathrm{L}$ \\
Color Pt/Co & $550 \mathrm{unities}$ & Grease and oil & $230.6 \mathrm{mg} / \mathrm{L}$ \\
Turbidity & $453 \mathrm{NTU}$ & $\mathrm{Al}$ & $0.983 \mathrm{mg} / \mathrm{L}$ \\
COD & $827 \mathrm{mg} / \mathrm{L}$ & $\mathrm{Cr}$ & $<0.06 \mathrm{mg} / \mathrm{L}$ \\
BOD & $444 \mathrm{mg} / \mathrm{L}$ & $\mathrm{Fe}$ & $1.40 \mathrm{mg} / \mathrm{L}$ \\
Total solids & $0.0015 \mathrm{mg} / \mathrm{L}$ & $\mathrm{Pb}$ & $0.42 \mathrm{mg} / \mathrm{L}$ \\
\hline
\end{tabular}

MBAS: Methylene-blue active substances, a measure of ionic surfactants; NTU: Nephelometric units; COD: Chemical oxygen demand; BOD: Biological oxygen demand. 
Initial wastewater characteristics were: $\mathrm{pH}=6.69$, conductivity $=1869 \mu \mathrm{S}$, turbidity 453 units, and COD = $827 \mathrm{mg} / \mathrm{L}$. Turbidity removals in the coagulation-flocculation assessments were as large as $37.2 \%$ for $\mathrm{FeCl}_{3}$ and $31.7 \%$ for guar gum and mucilage with $125 \mathrm{mg} / \mathrm{L}$. The turbidity removal with $50 \mathrm{mg} / \mathrm{L}$ of LBG was of $26.83 \%$ and $52 \%$ for mucilage.

Results regarding COD removal (Figure 3) were as follows. Best results were achieved using $\mathrm{FeCl}_{3}$ (93\%) at $150 \mathrm{mg} / \mathrm{L}$. Regarding the natural-gums, the best result was obtained with $150 \mathrm{mg} / \mathrm{L}$ of mesquite seed gum (57.7\%). Mesquite gum at 50 and $75 \mathrm{mg} / \mathrm{L}$ resulted in fairly good COD removals $(57.7 \%$ and $53.2 \%)$. Note that for the two lower concentrations, the COD removal for mesquite seed gum was inversely proportional to its concentration. The latter is a good remark, since the lower the coagulant dose, the lower the wastewater treatment total cost. Using guar gum, COD removals higher than $20 \%$ at polymer concentrations of 50 and $75 \mathrm{mg} / \mathrm{L}$ were achieved. The COD removal with Opuntia mucilage was very similar to that obtained with mesquite seed gum under these conditions, except at a concentration of $150 \mathrm{mg} / \mathrm{L}$. The concentration, $75 \mathrm{mg} / \mathrm{L}$ seems to be the optimum under the described conditions.

Although salinity removal is not a feature of the coagulation-flocculation process, in some cases dissolved salts were removed by a drag phenomenon (data not shown). Salinity removals were a function of the polymer/salt concentration. Values were quite low, i.e., between 0 and $5 \%$. Best salinity removals were observed when using guar and locust bean gums (150 mg/L) and mesquite gum $(125 \mathrm{mg} / \mathrm{L})$.

$\mathrm{pH}$ is a very important issue for coagulation-flocculation processes. First, it is desirable that no $\mathrm{pH}$ change is necessary for the initial wastewaters treatment. Second, it is desirable that final $\mathrm{pH}$ values are near neutrality after

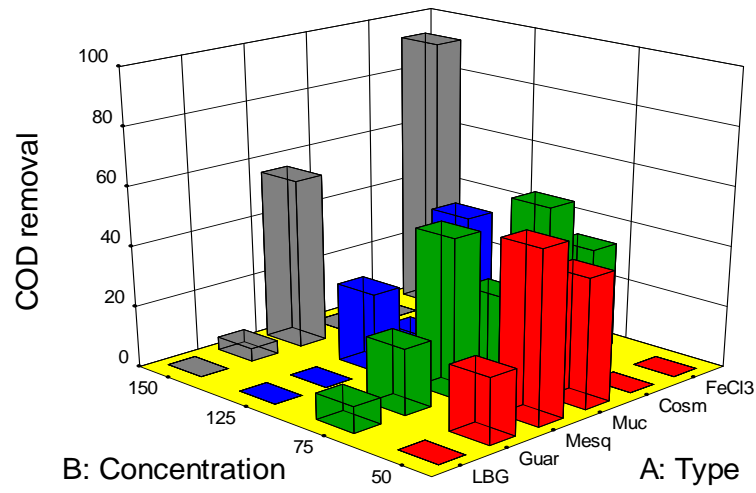

Figure 3. COD removal (\%) at pH 7 vs. biopolymer concentration (mg/L). LBG: locust bean gum; Guar:guar gum; Mesq: mesquite gum; Muc: Opuntia mucilage; Cosm: cosmedia guar; $\mathrm{FeCl}_{3}$ : ferric chloride. the coagulation-flocculation processes. In this respect, galactomannans, as well as $\mathrm{FeCl}_{3}$, slightly increased the $\mathrm{pH}$ value of the treated wastewaters. On the other hand, Opuntia mucilage promoted a diminution of the $\mathrm{pH}$ value, up to 5.94 units when using a $125 \mathrm{mg} / \mathrm{L}$ concentration (data not shown).

Sludge production of wastewater (in $\mathrm{mL} / \mathrm{L}$ ) is presented in Figure 4. It can be noted that for all the polymers and $\mathrm{FeCl}_{3}$, sludge production was higher as the polymer/salt concentration increased. Unexpectedly, mucilage showed a slight COD and turbidity removal at the assessed concentrations. In fact, mucilage assessments showed the highest sludge productions at concentrations of 125 and $150 \mathrm{mg} / \mathrm{L}$ (more than $2.5 \mathrm{~mL} / \mathrm{L}$ ). Other important sludge productions were found when using guar gum $(150 \mathrm{mg} / \mathrm{L})$ and mesquite seed gum $(125 \mathrm{~mL} / \mathrm{L})$. This issue is very interesting, since the amount of sludge produced in a real-scale process is determinant for the process. Produced sludges could be very light (low density) or heavy (high density), but useful design information is not complete if only the amount of produced sludge is reported.

It is important to remember [20] that $\mathrm{FeCl}_{3}$ works better at acidic $\mathrm{pH}$ values (4-5), so these assessments were influenced by that fact. In the future, new tests will be carried out using acidic values for wastewaters $\mathrm{pH}$ values.

\subsection{Effect of pH at $75 \mathrm{mg} / \mathrm{L}$}

Note that for a fixed amount of coagulant-flocculant $(75$ $\mathrm{mg} / \mathrm{L})$ (Figure 5), the best result at $\mathrm{pH}=5$ for biopolymers was observed for Opuntia mucilage with approximately a $50 \% \mathrm{COD}$ removal. In the case of $\mathrm{pH}=7$, the best result was for guar gum with a COD removal of $70 \%$, whereas, at $\mathrm{pH}=9$, both guar and LBG obtained a $65 \%$ of COD removal. At last, for $\mathrm{pH}=10$, the best results were obtained using mesquite seed gum, with a $90 \%$ COD removal.

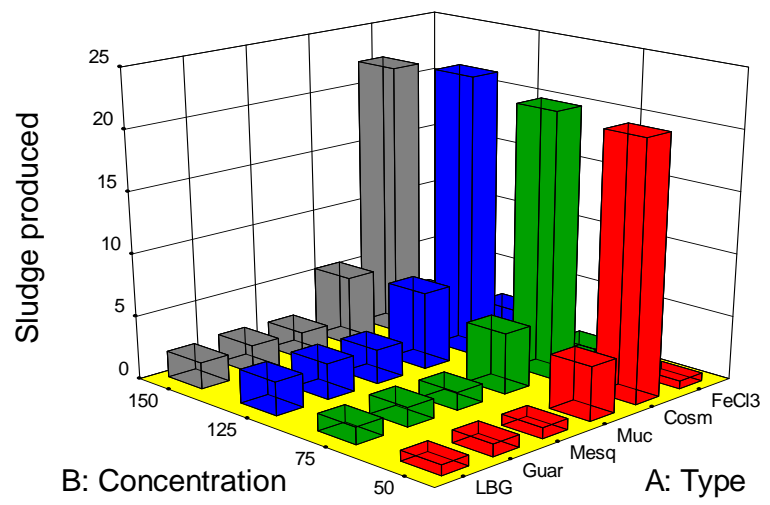

Figure 4. Sludge produced $(\mathrm{mL} / \mathrm{L})$ at $\mathrm{pH} 7$ vs. biopolymer concentration $(\mathrm{mg} / \mathrm{L})$. 


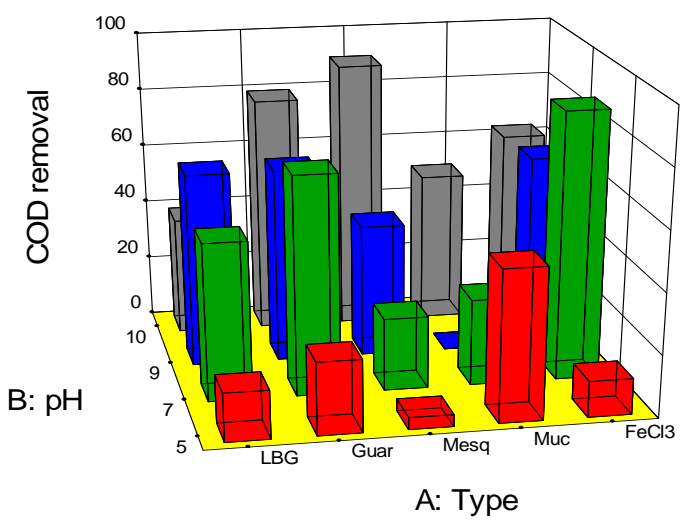

Figure 5. COD removal (\%) at fixed dose of $75 \mathrm{mg} / \mathrm{L}$ vs. $\mathrm{pH}$.

Sludge production for those experiments is shown in Figure 6. Sludge volumes were directly proportional to the $\mathrm{pH}$ value, but the relationship was not linear. For $\mathrm{pH}$ between 5 and 7 , sludge volumes of about $10 \mathrm{~mL} / \mathrm{L}$ were observed. For an alkaline $\mathrm{pH}$ value (9), these volumes were between 10 and $20 \mathrm{~mL} / \mathrm{L}$. Finally, for a $\mathrm{pH}$ value of 10 , sludges were up to $40-75 \mathrm{~mL} / \mathrm{L}$. We hypothesize that this amount of sludge is due to the effect of the $\mathrm{pH}$ on the biopolymer and the interaction with colloidal material present in the wastewaters, or due to the effect of $\mathrm{pH}$ on the colloidal material directly. Although data are not shown, modification of the wastewater $\mathrm{pH}$ value promoted sedimentation of quite high amounts of solids without the addition of any salt or polymer. This could imply that the sludge production was more related with the instability of the colloidal material at alkaline $\mathrm{pH}$ values.

\subsection{Effect of Concentration at $\mathbf{p H}=\mathbf{1 0}$}

The following experiments were carried out at a $\mathrm{pH}=10$ with different salt or biopolymer doses. At this point it is important to remember that modification of wastewaters $\mathrm{pH}$ is feasible, but it represents an operational cost. So, it will be necessary to take this into account when discussing COD removals at $\mathrm{pH}$ values different from the original $\mathrm{pH}$ value. The results of experiments at $\mathrm{pH}=10$ are presented in Figure 7. It is noticeable that COD removals were, in general, much better than those observed for the experiment with $\mathrm{pH}=7$. Secondly, it seems that all COD removals are an inverse function of salt or polymer dose.

If we take the case of Opuntia mucilage, very good COD removals were observed, i.e., $60 \%, 50 \%$, and $40 \%$ for polymer doses of 50,75 , and $100 \mathrm{mg} / \mathrm{L}$, respectively. In the case of guar gum, removals of $70 \%, 80 \%$ and $70 \%$ were obtained for doses of 50,75 , and $150 \mathrm{mg} / \mathrm{L}$. Obviously, the $150 \mathrm{mg} / \mathrm{L}$ is not a valid option. On the other hand for a dose of $125 \mathrm{mg} / \mathrm{L}$, inexplicably no COD removal was observed (Figure 7).
In the case of mesquite seed gum, attractive COD removals were obtained. For doses of 50, 75, 100, and 150 $\mathrm{mg} / \mathrm{L}$, removals of $60 \%, 90 \%, 80 \%$, and $50 \%$ were obtained. The use of $75 \mathrm{mg} / \mathrm{L}$ of mesquite seed gum at $\mathrm{pH}=$ 10 yielded the best result for COD removal in the entire study.

The results of sludge production under the same conditions can be observed in Figure 8; again, sludge production (in $\mathrm{mL} / \mathrm{L}$ ) was very dependent on the coagulant-flocculant dose, reaching values between 40 and 85 $\mathrm{mL} / \mathrm{L}$ for the whole set of experiments.

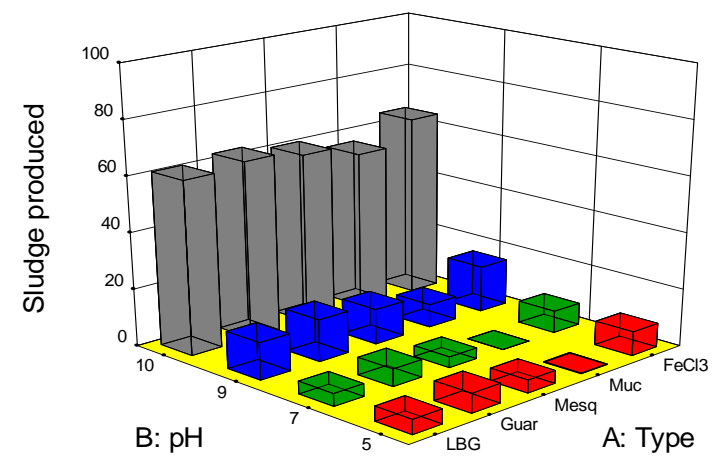

Figure 6. Sludge produced $(\mathrm{mL} / \mathrm{L})$ at fixed dose of $75 \mathrm{mg} / \mathrm{L}$ vs. pH.

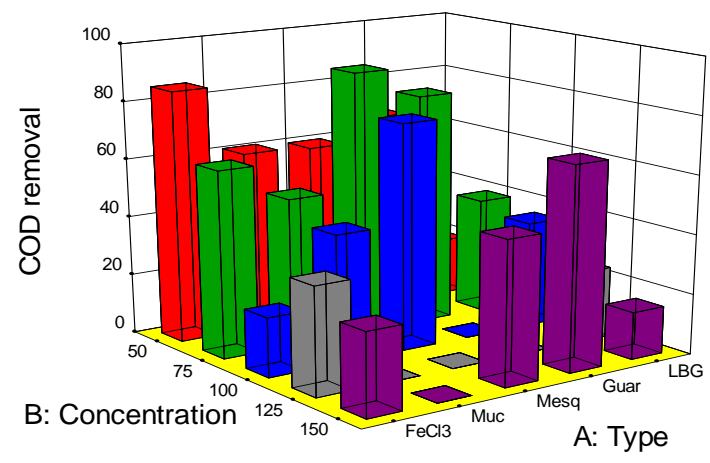

Figure 7. COD removal (\%) at pH 10 vs. biopolymer concentration (mg/L).

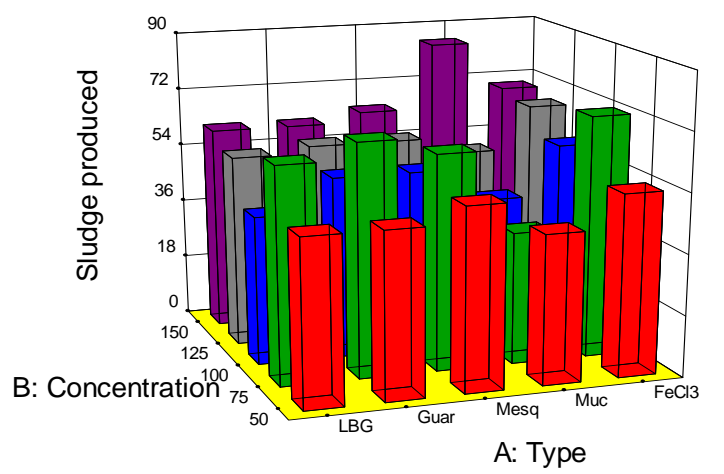

Figure 8. Sludge produced $(\mathrm{mL} / \mathrm{L})$ at $\mathbf{p H} 10$ vs. biopolymer concentration $(\mathrm{mg} / \mathrm{L})$. 


\section{Conclusions}

This work showed that all biopolymers guar, locust bean, and mesquite gums, as well as Opuntia mucilage, have potential to replace $\mathrm{Fe}$ or $\mathrm{Al}$ salts in the coagulation-flocculation process.

The COD, salt, and turbidity removals using biopolymers were quite good and comparable to those observed when using $\mathrm{FeCl}_{3}$. Sludge production was in general lower for biopolymers that those observed when using $\mathrm{FeCl}_{3}$, but it was very dependent on $\mathrm{pH}$ and amount of coagulant-flocculant employed.

Both Prosopis galactomannan and Opuntia mucilage were capable of treating municipal wastewaters with initial organic charges of about $827 \mathrm{mg} / \mathrm{L}$ as COD by coagulation-flocculation process with COD removals for mesquite seed gum of up to $90 \%(\mathrm{pH}=10$, dose of 75 $\mathrm{mg} / \mathrm{L})$ and about $60 \%(\mathrm{pH}=7$, doses of 50 and 150 $\mathrm{mg} / \mathrm{L}$ ). In the case of mucilage, $65 \%$ of the initial COD was removed at $\mathrm{pH}=10$ (dose of $50 \mathrm{mg} / \mathrm{L}$ ). These figures are very promising for the treatment of wastewaters, with environmental-friendly products.

In agreement with Yin (2010), it was corroborated that plant based coagulants can provide environmental benefits and numerous laboratory and scale studies are proving that the utilization of these products is technically feasible.

\section{Acknowledgements}

Funding is thanked to ICyT-DF; Grant PICSO10-8 and SIP-IPN project 2011933. Raw wastewaters were collected at San Juan Ixhuatepec (Estado de Mexico) wastewater treatment plant. Authors thank to G. Cuevas (Universidad de Guanjuato) which collected the Prosopis pods. The solvent-washing of the Prosopis bean powder and the determination of some polymer characteristics were made by L. Corzo (UPIBI-IPN).

\section{REFERENCES}

[1] SIRE, 2010.

http://sire.uca.es/sire/idex.do.html

[2] V. Mathur and N. K. Mathur, "Fenugreek and Other Lesser Known Legume Galactomannan-Polysaccharides: Scope for Developments," Journal of Scientific and Industrial Research, Vol. 64, No. 7, 2005, pp. 475-481.

[3] E. G. Azero and C. T. Andrade, "Characterization of Prosopis juliflora Seed Gum and Effect of Its Addition to $\kappa$-Carrageenan Systems," Journal of the Brazilian Chemical Society, Vol. 17, No. 5, 2006, pp. 844-850. doi:10.1590/S0103-50532006000500005

[4] L. Chairez-Martínez, J. A. Salazar-Motoya and E. G. Ramos-Ramírez, "Physicochemical and Functional Characterization of the Galactomanan Obtained from Mesquite
Seeds (Prosopis palida)," European Food Research Technology, Vol. 227, No. 6, 2008, pp. 1669-1676. doi:10.1007/s00217-008-0892-0

[5] C.-Y. Yin, "Emerging Usage of Plant-Based Coagulants for Water and Wastewater Treatment," Process Biochemistry, Vol. 45, No. 9, 2010, pp. 1437-1444. doi:10.1016/j.procbio.2010.05.030

[6] M. A. Cerqueira, A. C. Pinheiro, B. W. S. Souza, A. M. P. Lima, C. Ribeiro, C. Miranda, J. A. Teixeira, R. A. Moreira, M. A. Coimbra, M. P. Goncalves and A. A. Vicente, "Extraction, Purification and Characterization of Galactomannans from Non-Traditioal Sources," Carbohydrate Polymers, Vol. 75, No. 3, 2009, pp. 408-414. doi:10.1016/j.carbpol.2008.07.036

[7] PROSEA, Internet Resources, 2010. http://www.prosea.lipi.go.id/html

[8] “Agro Forestry Tree Database,” 2010. http://www.worlagroforestrycentry.org/sea/Products/AFD bases/af/index.asp

[9] D. McGarvie and H. Parolis, "The Mucilage of Opuntia ficus-indica," Carbohydrate Research, Vol. 69, No. 1, 1979, pp. 171-179. doi:10.1016/S0008-6215(00)85762-6

[10] C. Saenz, E. Sepulveda and B. Matsuhiro, “Opuntia spp. Mucilage's: A Functional Component with Industrial Perspectives," Journal of the Arid Environments, Vol. 57, No. 3, 2004, pp. 275-290. doi:10.1016/S0140-1963(03)00106-X

[11] E. Sepúlveda, C. Saez, E. Aliaga and C. Aceituno, "Extraction and Characterization of Mucilage in Opuntia spp.," Journal of Arid Environments, Vol. 68, No. 4, 2007, pp. 534-545. doi:10.1016/j.jaridenv.2006.08.001

[12] F. M. Goycoolea and A. Cardenas, "Pectins from Opuntia spp.: A Short Review," Journal of the Professional Association for Cactus Development, Vol. 2, 2003, pp. 152-159.

[13] J. D. Zhang, F. Zhang, Y. H. Luo and H. Yang, "A Preliminaty Study on Cactus as Coagulant in Water Treatment," Process Biochemistry, Vol. 41, No. 3, 2006, pp. 730-733. doi:10.1016/j.procbio.2005.08.016

[14] P. Miretzly, C. Muñoz and A. Carrillo-Chavez, "Experimental Binding of Lead to a Low Cost on Biosorbent: Nopal (Opuntia streptacantha)," Bioresource Technology, Vol. 99, No. 5, 2008, pp. 1211-1217. doi:10.1016/i.biortech.2007.02.045

[15] S. M. Miller, E. J. Furgate, V. O. Craver, J. A. Smith and J. B. Zimmerman, "Towards Understanding the Efficacy and Mechanism of Opuntia spp. as a Natural Coagulant for Potential Application in Water Treatment," Environmental Science and Technology, Vol. 42, No. 12, 2008, pp. 4274-4279. doi:10.1021/es7025054

[16] E. R. Bandala, F. J. Camargo and L. G. Torres, “Application of Natural Surfactants in the Treatment of Wastewaters Generated in the Hydrocarbon-Contaminated SoilWashing," Journal of Enviromental Science and Health: Part A, 2012.

[17] S. Carpinteyro-Urban, J. Yáñez and L. G. Torres, "Coagulation-Flocculation of Wastewaters Employing Guar, Locust Bean and Mesquige Gums, as well as Opuntia 
Mucilage," Proceedings of the 2nd IWA Mexico Young Water Professional Conference, Queretaro, Mexico, 12-14 April 2010.

[18] P. M. Nacheva, L. T. Bustillos, E. R. Camperos, S. L. Armenta and L. C. Vigueros, "Characterization and Coagulation-Flocculation Treatability of Mexico City Wastewater Applying Ferric Chloride and Polymers," Water Science and Technology, Vol. 34, No. 3-4, 1996, pp. 235247. doi:10.1016/0273-1223(96)00579-3

[19] APHA, AWWA, WPFC, "Standard Methods for the Examination of Water and Wastewater," 18th Edition, American Public Health Association, Washington DC, 1995.

[20] L. K. Wang, Y.-T. Hung and N. K. Shammas, "Physicochemical Treatmet Processes," Humana Press, New York City, 2005. doi: 10.1385/159259820x 